\title{
EdUCAÇÃO FÍSICA ESCOLAR NO ENSINO MÉdIO INTEGRADO: LIMITES E POSSIBILIDADES DE UMA PROPOSTA DE INTERVENÇÃO
}

\author{
SCHOLAR PHYSICAL EDUCATION IN INTEGRATED HIGH SCHOOL: LIMITS \\ AND POSSIBILITIES OF AN INTERVENTION PROPOSAL
}

DOI: http://dx.doi.org/10.23926/RPD.2526-2149.2020.v5.n1.p100-120.id635

\section{Luciano de Almeida}

Doutorado em Educação nas Ciências (UNIJUÍ)

Professor de Educação Física (IFFAR/ Campus Santo

Augusto)

luciano.almeida@iffarroupil ha.edu.br

\section{Fabrício Döring Martins}

Doutorando em Ciências do Movimento Humano

(UFRGS)

Professor de Educação Física (IFFAR/ Campus Santo Augusto) fabricio.martins@iffarroupil ha.edu.br
Resumo: O presente artigo tem por objetivo identificar e analisar os limites e possibilidades de uma proposta de intervenção, desenvolvida no ano de 2019 junto aos alunos dos Cursos Técnicos Integrados ao Ensino Médio de um campus do Instituto Federal Farroupilha. Para isso, esta investigação de natureza qualitativa e de caráter descritivo, referenciada na perspectiva metodológica da pesquisa-ação, foi organizada em quatro fases interligadas: planejamento, ação, descrição e avaliação. Teve um movimento contínuo e sistemático, contando com a participação de 396 alunos e dos 2 professores de EF do campus. Dentre os limites da proposta de intervenção, destacamos a dificuldade de promover uma integração de conhecimentos relacionados à educação básica e profissional. Nas possibilidades, a reafirmação da importância de nosso protagonismo na contingência de nossa ação interventiva e reflexiva, no tratamento dado ao caráter processual do conhecimento e no diálogo constante e sempre renovado pela crítica dos pares.
Palavras-chave:
Educação;
Conhecimento;
Educação

Profissionalizante; Currículo.

\begin{abstract}
This article aims to identify and analyze the limits and possibilities of an intervention proposal, developed in 2019 with students of Technical Courses Integrated to High School on a campus of the Federal Institute Farroupilha. In this sense, a qualitative and descriptive investigation, referenced under the methodological perspective of action research, was organized in four related phases: planning, action, description, and evaluation. There was a continuous and systematic movement, with the participation of 396 students and the 2 PE teachers on campus. Among the limits of the intervention proposal, we highlight the difficulty of promoting the integration of knowledge related to basic and professional education. In terms of possibilities, the reaffirmation of the importance of our role for an interventional and reflective action in the treatment given to the procedural nature of knowledge, and in the constant and always renewed dialogue by the criticism of peers.
\end{abstract}

Keywords: Education; Knowledge; Vocational Education; Curriculum. 


\section{INTRODUÇÃO}

A Educação Física escolar (EFE), ao longo de sua constituição, vem passando por diferentes mudanças em seus discursos legitimatórios e em seus marcos legais, algo que exige dela uma responsabilidade de passar de um espaço de atividades (“exercitar-se”) para um campo de tematização capaz de tratar pedagogicamente os temas relacionados à cultura corporal de movimento e produzir saberes acerca desses temas (ALMEIDA; FENSTERSEIFER, 2018).

Pensando nessa responsabilidade, temos feito um esforço para assumir o nosso protagonismo através da elaboração e reelaboração constante de algumas proposições nos diferentes contextos em que atuamos, na tentativa de contribuir (mesmo que minimamente) para a problematização das questões relacionadas ao conhecimento na EFE, aos diferentes tipos de saberes e dimensões, com o intuito de proporcionar aos nossos alunos a apropriação do acervo cultural produzido pela humanidade em torno do se-movimentar e das práticas corporais que se configuraram em saberes sistematizados e foram materializadas nos currículos e conteúdos escolares para que estes alunos sintam-se em casa no mundo (GONZÁLEZ; FENSTERSEIFER, 2010).

Já evidenciamos em estudos anteriores (ALMEIDA; FENSTERSEIFER, 2006; 2014; 2018) que a falta de uma proposição para a EFE, materializada em uma proposta de intervenção (ou organização curricular), tem nos levado (nosso campo de tematização de uma maneira mais ampla) a reduzir nossas aulas à incorporação de algumas modalidades esportivas e a outras atividades referenciadas no lazer $^{1}$, algo que não vem ao encontro de um dos objetivos da instituição escolar, a saber, estimular, "provocar e facilitar a reconstrução dos conhecimentos, atitudes e formas de conduta que os alunos e alunas assimilam direta e acriticamente nas práticas sociais de sua vida anterior e paralela à escola" (SACRISTÁN; GÓMEZ, 1998, p. 25).

Nesse sentido, enfrentamos neste texto o desafio de responder, mesmo que provisoriamente, algumas questões que permeiam nossas "escolhas" na elaboração e reelaboração constante de nossa proposta de intervenção: os temas estruturantes escolhidos são os mais pertinentes a ser abordados em nossas aulas no ensino médio integrado e estão vinculados aos princípios que norteiam a instituição escolar (republicana e democrática)? Os conteúdos tematizados possuem maior relevância? A determinação da carga horária dá conta de atender os diferentes saberes (corporais e conceituais) em nossas aulas? Os critérios

\footnotetext{
${ }^{1}$ Essa constatação se confirma nos diagnósticos realizados com nossos alunos a cada novo ano letivo (passagem do ensino fundamental para o ensino médio integrado), em que estes revelam que tiverem vivências de duas ou três modalidades esportivas nas aulas de EF no âmbito do lazer.
} 
utilizados para essa organização estão condizentes com os diferentes níveis de aprendizagem de nossos alunos? Os instrumentos de avaliação utilizados dão conta da complexidade do conhecimento na EFE? Estamos tratando das especificidades de nosso campo de tematização articuladas com a educação profissional e tecnológica (integração curricular)?

Sem a pretensão de formular respostas "definitivas" para essas questões, o presente artigo busca identificar e analisar os limites e possibilidades de uma proposta de intervenção, desenvolvida no ano de 2019 junto aos alunos dos Cursos Técnicos Integrados ao Ensino Médio de um campus do Instituto Federal Farroupilha, destacando os critérios estabelecidos para a sua elaboração (marcos legais, referenciais curriculares, projeto político-pedagógico, planos de estudo da disciplina, realidade dos alunos - o que sabem?) e as dificuldades enfrentadas durante a intervenção, o que a nosso ver potencializa a continuidade do exercício da crítica e a revisão constante de "novas" proposições.

Como forma de sistematizar este estudo, apresentamos em um primeiro momento o aporte teórico consultado e construído para a elaboração de nossa proposta de intervenção e seus desdobramentos para pensar o campo de conhecimentos da EFE em suas diferentes dimensões e saberes; na sequência, destacamos o desenho de nossa pesquisa-ação que parte dos limites da proposta anterior (2018) e se desenvolve no planejamento, ação, descrição e avaliação do trabalho realizado em 2019; no decorrer do texto, também apresentamos os limites e possibilidades dessa intervenção, destacando a dificuldade em estabelecer uma relação entre o tempo disponível e o tempo necessário para a abordagem dos temas estruturantes e diferentes tipos de saberes e a dificuldade de articular e/ou vincular as especificidades de nosso campo de tematização ao currículo integrado; por fim, reafirmamos a importância de nosso protagonismo na elaboração e reelaboração constante de nossa ação interventiva e reflexiva.

\section{2 "NOSSA" PROPOSTA DE INTERVENÇÃO}

Enfatizamos a expressão "nossa" proposta de intervenção por entendermos que ela representa o reconhecimento de que nos constituímos nas relações que estabelecemos com o outro e na apropriação dos referenciais que vamos construindo durante todo o nosso processo formativo. Cabe destacar que esse processo formativo, como lembra (MALDANER, 2006), acontece mesmo antes de nossa entrada na formação inicial, como um processo permanente que tem início em nossa formação escolar (educação básica), quando estabelecemos contato com nossos professores e, em nosso caso em especial, com os professores de Educação Física, e 
continua durante toda nossa trajetória acadêmica (formação inicial) e profissional (formação permanente).

É possível afirmar que essa proposta vem sendo elaborada e reelaborada desde nossa entrada no universo profissional (por volta do ano 2000), nos diferentes contextos em que atuamos ${ }^{2}$, a partir do diálogo constante e sempre renovado com as obras e autores que tratam da EFE (em suas diferentes matrizes teóricas e abordagens didático-pedagógicas), com os marcos legais, com nossa atuação profissional e com a crítica dos pares ${ }^{3}$.

A partir dessas notas iniciais, passamos a expor alguns critérios que utilizamos para a reelaboração da última versão (provisória) de nossa proposta de intervenção. Concordando com González e Fensterseifer (2010), destacamos dois elementos que consideramos centrais para essa proposição: o primeiro estaria relacionado à ideia de identificar o campo de conhecimentos particulares que justificam sua pertinência como disciplina escolar; e o segundo diz respeito aos conhecimentos culturais, dos quais a EF se apropria (se ocupa), e que merecem ser tratados pedagogicamente, diferentemente de outros espaços sociais.

Esse campo de conhecimentos referido pelos autores desdobra-se em três dimensões que, se bem vinculadas, constituiriam tipos diferentes de conhecimentos que contemplariam as especificidades desse campo de tematização enquanto disciplina escolar; são elas: 1) as possibilidades do se-movimentar dos seres humanos; 2) as práticas corporais sistematizadas, vinculadas ao campo do lazer, ao cuidado do corpo e à promoção da saúde e; 3) as representações sociais que atravessam esse universo (composta pelos conceitos).

A primeira dimensão proposta pelos autores, referente às possibilidades do semovimentar, estaria relacionada ao esforço de oportunizar a apropriação das diferentes manifestações da cultura corporal de movimento (pela - na experiência do seu se-movimentar), para descobrir e ampliar outras possibilidades de movimento, conhecimento do próprio corpo e de relacionar-se com o ambiente físico (material) e com o outro (social). Almeida e Fensterseifer (2018) destacam duas perspectivas para o se-movimentar: a primeira relacionada à ideia de "exploração" (principalmente corporal), a partir das experiências vividas pelas crianças através de jogos, brincadeiras, atividades expressivas, etc., potencializando novas

\footnotetext{
${ }^{2}$ Essa afirmação revela o caráter de continuidade de nossas proposições nos diferentes contextos e níveis de ensino em que atuamos, uma vez que fazem parte do nosso processo formativo durante nossa trajetória docente e nos dão um aporte teórico (e prático) para renovadas proposições.

${ }^{3}$ Destacamos alguns autores e obras (e marcos legais) que fizeram/fazem parte de nossas diferentes proposições, em suas diferentes "versões": Coletivo de Autores (1992), Betti (1994), Parâmetros Curriculares Nacionais (BRASIL, 1998), Kunz (2000), Bracht (2003), Fensterseifer e González (2007), González e Fensterseifer (2009; 2010), González e Fraga (2009; 2012), Base Nacional Comum Curricular (2016; 2017), além de outros.
} 
possibilidades de se-movimentar, para além de seu entorno imediato; a segunda vinculada à apropriação das manifestações relacionadas às práticas corporais de forma mais sistematizada, reunindo tanto os saberes produzidos através da experiência corporal, quanto os conhecimentos conceituais sobre as mesmas.

A segunda dimensão proposta por González e Fensterseifer (2010), no que tange às práticas corporais sistematizadas, vinculadas ao campo do lazer, o cuidado com o corpo e à promoção da saúde, vincula-se à segunda perspectiva do se-movimentar proposta por Almeida e Fensterseifer (2018), uma vez que se apropria do universo das manifestações da cultura corporal de movimento, através da experiência com os temas que foram (e são) incorporados pelo nosso campo de tematização e se configuraram em práticas corporais sistematizadas, tratando-os como produções humanas em seus diferentes saberes (corporais, conceituais, éticos, estéticos e expressivos). Essas práticas corporais constituem-se em práticas sociais que possuem alguns elementos em comum: “a) o movimento corporal como elemento essencial; b) uma organização interna (de maior ou menor grau) pautada por uma lógica específica; e c) serem produtos culturais vinculados com o lazer/entretenimento e/ou o cuidado do corpo e a saúde" (GONZÁLEZ; FENSTERSEIFER, 2010, p. 15).

Por fim, a terceira dimensão do conhecimento, segundo os autores, refere-se às representações sociais que atravessam esse universo (composta pelos conceitos), que nos dão indicativos para pensar e refletir acerca da origem e a dinâmica das transformações que ocorreram (ocorrem) nas representações e práticas sociais relacionadas com as "atividades corporais de tempo livre, o cuidado e a educação do corpo, seus vínculos com a organização da vida coletiva e individual, bem como os agentes sociais envolvidos em sua produção (estado, mercado, mídia, instituições esportivas, organizações sociais etc.)" (GONZÁLEZ; FENSTERSEIFER, 2010, p. 16).

Para pensar nos desdobramentos das dimensões do conhecimento propostas por González e Fensterseifer (2010), recorremos ao Referencial Curricular do Rio Grande do Sul (GONZÁLEZ; FRAGA, 2009), o qual nos apresenta um mapa conceitual para uma abordagem das relações de ensino e aprendizagem na $\mathrm{EF}$ ao longo dos anos escolares em termos de criticidade e complexidade. Os autores apresentam uma "categorização" que nos permite pensar na complexidade e ambivalência no tratamento dado aos diferentes tipos de saberes produzidos em nosso campo de tematização, que são "divididos" nos eixos "saberes corporais" e "saberes conceituais". Os primeiros sustentam-se na construção de experiências predominantemente a partir do movimento, que promove um conhecimento "encarnado" e necessita ser experienciado 
pelo sujeito através da credencial de vivência própria (GADAMER, 2008); já os segundos, relativos ao conjunto de dados e conceitos que descrevem e explicam diferentes aspectos relativos às práticas corporais sistematizadas, proporcionam uma "leitura" mais alargada em função da diversidade de significados sobre os mesmos.

Esses eixos ("saberes corporais" e "saberes conceituais") são apresentados ainda, por González e Fraga (2009), em subeixos que permitem uma leitura mais detalhada acerca da diversidade de temas e subtemas estruturadores a ser abordados nas aulas de EF. Os "saberes corporais" estão organizados em dois subeixos: "saber praticar" e "praticar para conhecer". Esses subeixos nos auxiliam na organização do tempo curricular (carga horária) de acordo com as expectativas em relação à aprendizagem de cada prática corporal e ao nível de proficiência que se espera em relação às mesmas. Por exemplo, no tratamento dado a um esporte de quadra dividida (voleibol), o tempo destinado a essa modalidade poderia ser maior devido, dentre outros fatores, ao potencial de exploração da mesma no tempo livre dos alunos ("saber praticar"). Por outro lado, a abordagem de um esporte de campo e taco (beisebol), poderia destinar um tempo menor, por se tratar de uma modalidade pouco conhecida, uma vez que não faz parte do contexto de determinadas comunidades escolares (como em nosso caso, por exemplo) ("praticar para conhecer").

Os "saberes conceituais", por sua vez, também são apresentados em dois subeixos: "conhecimento técnico" e "conhecimento crítico". O primeiro tenta articular a abordagem de conceitos necessários para entender as características e o "funcionamento" de determinada prática corporal em uma dimensão mais operacional, como por exemplo no estudo dos efeitos de um programa de exercícios (princípios do treinamento esportivo) para a manutenção ou melhoria da condição física dos alunos. Com relação ao subeixo "conhecimento crítico", podemos perceber uma abordagem das práticas corporais em diferentes contextos socioculturais em relação à sua produção e transformação, devido à sua vinculação às dimensões éticas e estéticas de cada período histórico em um determinado contexto que as gerou, algo que potencializa aos nossos alunos uma leitura mais ampla e uma reflexão acerca das possibilidades de usufruir determinadas práticas "no lugar onde moram, os recursos disponíveis (públicos e privados) para tal, os agentes envolvidos com o seu desenvolvimento, dentre outros aspectos" (GONZÁLEZ; FRAGA, 2009, p. 122).

Nesse sentido, apresentamos três quadros que, acreditamos, articulam as dimensões propostas por González e Fensterseifer (2010) com os saberes considerados fundamentais nos referenciais elaborados por González e Fraga $(2009 ; 2012)$, uma vez que contemplam os 
diferentes tipos de conhecimento com as manifestações culturais relacionadas ao corpo, ao semovimentar, ao campo do lazer e à promoção da saúde e à intencionalidade pedagógica em uma disciplina escolar. Uma das limitações enfrentadas na reelaboração da proposta está vinculada à ideia de "eleger" alguns temas estruturadores (devido à pluralidade de manifestações relacionadas à cultura corporal de movimento) que, entendemos, deveriam fazer parte de um "programa mínimo" para a EFE, a ser desenvolvido ao longo dos anos escolares em termos de complexidade e criticidade. Reconhecemos que essa é uma condição de nossa tarefa educativa, uma vez que realizamos algumas escolhas que acreditamos dar conta (minimamente) das dimensões do conhecimento e de diferentes tipos de saberes de nosso campo de tematização e seus vínculos com a educação escolar (republicana e democrática), algo que não acontece sem "perdas".

É preciso explicitar que na construção de nossa proposta de intervenção não nos preocupamos apenas com uma seleção de conteúdos, como pode parecer nos quadros que representam a sua sistematização, mas reconhecemos que o saber escolar também se materializa neles, uma vez que

sem conteúdo não há ensino, qualquer projeto educativo acaba se concretizando na aspiração de conseguir alguns efeitos nos sujeitos que se educam. Referindo-se estas afirmações ao tratamento científico do ensino, pode-se dizer que sem formalizar os problemas relativos aos conteúdos não existe discurso rigoroso nem científico sobre o ensino, porque estaríamos falando de uma atividade vazia ou com significado à margem do para que serve (SACRISTAN, 2000, p. 120).

Quadro 1 - Síntese da organização curricular das turmas de primeiros anos para o ano letivo de 2019

\begin{tabular}{|c|c|c|c|c|c|c|}
\hline \multicolumn{7}{|c|}{$\begin{array}{l}\text { ORGANIZAÇÃO CURRICULAR DA EDUCAÇÃO FÍSICA - PRIMEIROS ANOS - } 2019 \\
\text { CURSOS TÉCNICOS INTEGRADOS AO ENSINO MÉDIO COM } 80 \text { AULAS E } 40 \text { AULAS ANUAIS }\end{array}$} \\
\hline $\begin{array}{c}\text { TEMAS } \\
\text { ESTRUTURANT }\end{array}$ & Unidade de & \multicolumn{3}{|c|}{ Unidade de Esportes I } & \multirow{2}{*}{ 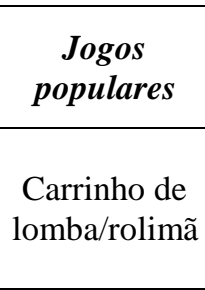 } & \multirow{2}{*}{$\begin{array}{c}\begin{array}{c}\text { Unidade de } \\
\text { Práticas de } \\
\text { Aventura I }\end{array} \\
\begin{array}{c}\text { Slackline } \\
\text { Corrida de } \\
\text { orientação }\end{array}\end{array}$} \\
\hline $\begin{array}{l}\text { SUBTEMAS/ } \\
\text { CONTEÚDOS }\end{array}$ & $\begin{array}{c}\text { Exercício } \\
\text { Físico - } \\
\text { Capacidades } \\
\text { físicas básicas }\end{array}$ & Invasão & $\begin{array}{c}\text { Técnico } \\
\text { combinatório }\end{array}$ & Campo e taco & & \\
\hline $\begin{array}{l}\text { PREVISÃO DE } \\
\text { AULAS }\end{array}$ & $10 *$ e $08 * *$ & $24 *$ e $10 * *$ & $14 *$ e $06^{* *}$ & $18 *$ e $08 * *$ & $04 *$ e $02 * *$ & $10 *$ e $06 * *$ \\
\hline
\end{tabular}

Fonte: acervo particular 
Quadro 2 - Síntese da organização curricular das turmas de segundos anos para o ano letivo de 2019.

\begin{tabular}{|c|c|c|c|c|c|}
\hline \multicolumn{5}{|c|}{ ORGANIZAÇÃO CURRICULAR DA EDUCAÇÃO FíSICA - SEGUNDOS ANOS - 2019 } \\
CURSOS TÉCNICOS INTEGRADOS AO ENSINO MÉDIO COM 80 AULAS E 40 AULAS ANUAIS
\end{tabular}

Fonte: acervo particular

Quadro 3 - - Síntese da organização curricular das turmas de terceiros anos para o ano letivo de 2019

\begin{tabular}{|c|c|c|c|c|c|}
\hline \multicolumn{5}{|c|}{ ORGANIZAÇÃo CURRICULAR DA EDUCAÇÃo FísICA - TERCEIROS ANOS } \\
CuRsos TÉCNICOS INTEGRADOS AO ENSINO MÉDIO - 2019 - 80 AULAS E 40 AULAS ANUAIS \\
\hline $\begin{array}{c}\text { TEMAS } \\
\text { ESTRUTURANTES }\end{array}$ & $\begin{array}{c}\text { Unidade de } \\
\text { Ginástica III }\end{array}$ & \multicolumn{2}{|c|}{ Unidade de Esportes III } & $\begin{array}{c}\text { Unidade de Práticas de } \\
\text { Aventura III }\end{array}$ \\
\hline $\begin{array}{c}\text { SUBTEMAS/ } \\
\text { CONTEÚDOS }\end{array}$ & $\begin{array}{c}\text { Exercício Físico - } \\
\text { Programa de } \\
\text { treinamento }\end{array}$ & Invasão & $\begin{array}{c}\text { Quadra } \\
\text { dividida }\end{array}$ & $\begin{array}{c}\text { Projeto "Práticas de } \\
\text { aventura" - trekking, } \\
\text { escalada, rapel, rafting e } \\
\text { canoagem }\end{array}$ \\
\hline $\begin{array}{c}\text { PREVISÃO DE } \\
\text { AULAS }\end{array}$ & $14 *$ e $10^{* *}$ & $24 *$ e $12^{* *}$ & $20^{*}$ e $08^{* *}$ & $12^{*}$ e $06^{* *}$ & $10^{*}$ e 04** \\
\hline
\end{tabular}

Fonte: acervo particular

Apesar desses quadros serem apresentados de maneira compartimentada, entendemos que as diferentes dimensões e saberes não podem ser ensinados de forma separada. Foram apresentados nessa sistematização para possibilitar uma leitura dos desdobramentos da proposta, visando um melhor entendimento. Chamamos a atenção para o fato de que alguns temas estruturantes não foram contemplados em nossa organização, planejamento e intervenção por diferentes razões e escolhas, as quais serão abordadas no decorrer do artigo.

\section{Percurso Metodológico}

Adotamos como metodologia de referência para delinear o presente percurso investigativo a pesquisa-ação e/ou investigação-ação, por relacionar dois tipos de objetivos: objetivo prático, com vistas a contribuir para o levantamento de soluções e propostas de "solução" para o problema central da pesquisa; e o objetivo de conhecimento, visando obter informações de difícil acesso por meio de outros procedimentos, aumentando assim nosso conhecimento de determinadas situações (THIOLLENT, 1988). Essa relação nos permitiu/permite identificar as questões centrais ou os problemas da investigação (no caso da proposta de intervenção), planejar e propor alternativas para a "resolução" desses problemas, realizar a intervenção, avaliar suas possibilidades e limites e, novamente, propor alternativas de 
intervenção, em um movimento contínuo, sistemático e empiricamente fundamentado para aprimorar a prática (TRIPP, 2005).

Nossa proposta de investigação foi organizada em quatro momentos articulados e interdependentes, com base nas quatro fases do ciclo básico da investigação-ação proposta por Tripp (2005): planejamento; ação; descrição e avaliação. Na fase de planejamento foi elaborada a proposta de intervenção do campus, pautada pelos limites e possibilidades da intervenção pedagógica (proposta de intervenção) realizada no ano de 2018; pelos marcos legais e referenciais teóricos da área, levamos em conta também, as especificidades do contexto (carga horária, estrutura, etc.) e do curso (especificidades dos 5 cursos técnicos integrados ao ensino médio - Administração, Agropecuária, Alimentos, Informática e Agroindústria - esse último na modalidade de Educação de Jovens e Adultos - EJA/EPT ${ }^{4}$ ).

Na fase da ação (execução), desenvolvemos as Unidades Didáticas de cada tema/eixo estruturador nas diferentes "séries" $\left(1^{\text {os }}, 2^{\text {os }}\right.$ e $3^{\text {os }}$ anos) e turmas dos cursos técnicos integrados ao ensino médio do campus. No que tange à fase de descrição, monitoramos e descrevemos minuciosamente os efeitos da ação em situação. Os registros das aulas foram realizados em diário de campo, uma vez que esse permite a coleta de informações e análise das situações em estudo durante todo o processo de investigação (TRIVIÑOS, 1987); também registramos em fotos, vídeos, depoimentos, textos informativos e relatórios dos estudantes sobre as mesmas. Na fase de avaliação refletimos sobre os resultados da ação (mudança na prática) em cada aula, destacando: quais aspectos foram atendidos? Quais precisam de uma revisão? E, por fim, uma análise aprofundada de cada Unidade Didática e de todo o processo investigativo.

Cabe destacar, ainda, que o desenho de nossa pesquisa contempla, a nosso ver, os principais aspectos da pesquisa-ação educativa propostos por Betti e Franco (2014), uma vez que observa o caráter ontológico, epistemológico e metodológico da investigação. Ontologicamente, porque somos os protagonistas da prática, que conhecem a realidade e tentam transformá-la; epistemologicamente, porque buscamos um saber compartilhado que emerge do processo e não do produto; metodologicamente, porque fazemos uma prática dialógica e participamos de toda a construção dos processos de ensinar e aprender, da negociação, dos acordos, da colaboração, da efetiva participação na/da leitura da realidade e do apontamento de

\footnotetext{
${ }^{4}$ Não vamos trazer para a discussão aspectos relacionados à modalidade da Educação de Jovens e Adultos Educação Profissional e Tecnológica (EJA/EPT), tendo em vista que a EF está inserida apenas no $2^{\circ}$ ano desses cursos, e não faríamos o devido aprofundamento, necessário para a discussão. Vamos fazer uma abordagem mais aprofundada em outro texto.
} 
possíveis soluções e hipóteses de ação para a construção do conhecimento (BETTI; FRANCO, 2014).

Para a análise e interpretação dos dados produzidos, recorremos à análise de conteúdo proposta por Bardin (2011), que foi organizada em pré-análise (organização), exploração do material (codificação e categorização) e tratamento dos resultados obtidos e interpretação (informações fornecidas pela análise). Com esses resultados, redefinimos nossa proposta de intervenção (organização curricular) e as Unidades Didáticas para uma nova intervenção, num movimento contínuo de investigação-ação, além de materializar nossas reflexões no presente texto.

Participaram deste estudo os 2 (dois) professores de Educação Física (nós) de um campus do Instituto Federal de Educação, Ciência e Tecnologia Farroupilha, sendo que os mesmos são nomeados em regime de dedicação exclusiva, além dos 396 (trezentos e noventa e seis) alunos que estavam matriculados e frequentando os Cursos Técnicos Integrados ao Ensino Médio no ano letivo de 2019. O estudo seguiu todas as normas éticas para a pesquisa com seres humanos, e a participação se deu de forma voluntária, tanto dos sujeitos quanto da instituição. Os participantes assinaram o Termo de Consentimento Livre e Esclarecido e o projeto foi aprovado pelo Comitê de Ética com o parecer consubstanciado de número 3.284.279.

\section{Limites E POSSIBILIDAdeS de NOSSA PROPOSTA DE INTERVENÇÃo: COM A PALAVRA OS ALUNOS}

Sem a pretensão de uma retomada exaustiva acerca dos elementos que embasaram a construção de nossa proposta de trabalho (já abordados anteriormente), ou uma descrição minuciosa de como foram desenvolvidas nossas Unidades Didáticas (em cada tema estruturador), passamos a relatar (resumidamente) algumas situações experienciadas e tematizadas durante o desenvolvimento da proposta, que nos auxiliam na problematização das questões referentes às dimensões do "conhecer" em nosso campo de tematização, articulandoas aos referenciais deste estudo, percebendo suas possibilidades e limites a partir do diálogo constante e sempre renovado com nossa ação interventiva e reflexiva, o olhar de nossos alunos, as obras que tratam sobre o tema e a crítica de nossos pares.

Como já vimos anteriormente (quadros 1, 2 e 3), organizamos nossa proposta em torno de temas estruturantes (Ginástica, Esportes, Jogos Populares ${ }^{5}$ e Práticas de Aventura), que se

\footnotetext{
${ }^{5}$ A Unidade Didática de Jogos Populares foi desenvolvida apenas no primeiro ano dos cursos técnicos integrados ao ensino médio, e por isso não vai ser abordada no presente texto, uma vez que nossa discussão
} 
desdobraram no desenvolvimento de Unidades Didáticas (Unidades I, II e III em cada tema), na tentativa de sistematizar uma "sequência" de conteúdos a ser abordados nos três anos dos cursos técnicos integrados ao ensino médio em termos de complexidade (aprofundamento teórico e prático em cada unidade durante os anos escolares).

Nas Unidades (I, II e III) de Exercício Físico, que se constituem em um subtema do tema estruturante Ginástica (ou ginásticas de condicionamento físico) e estão vinculadas aos cuidados do corpo e à promoção da saúde (em especial), optamos por fazer uma abordagem dos "conteúdos" capacidades físicas básicas (I), treinamento aeróbico e de força (II) até chegar à elaboração e desenvolvimento de um programa de exercícios físicos (a partir dos princípios do treinamento esportivo) (III), observando os tipos de saberes (corporais e conceituais) no tratamento dos mesmos em cada unidade desenvolvida. No início do desenvolvimento de cada uma das unidades, realizamos testes de aptidão física relacionada à saúde (AFRS), no intuito de termos alguns parâmetros para abordarmos as relações entre saúde e exercício físico. Os resultados desses testes, além de permitir que os alunos percebam os limites de seu próprio corpo e seu nível de condicionamento físico, também nos auxiliam a justificar nossa escolha no tratamento dessas unidades, tendo em vista que esses indicam que muitos alunos não conseguem atingir os resultados mínimos indicados para uma boa saúde, principalmente no que se refere à resistência cardiorrespiratória ${ }^{6}$.

$\mathrm{Na}$ Unidade I, os alunos apropriam-se dos conceitos referentes às capacidades físicas básicas (condicionais e coordenativas), construindo um aporte teórico que é experienciado no plano corporal através da vivência de cada capacidade e registrada no quadro de sensações corporais, algo que propicia um saber orgânico dos diferentes saberes de maneira complementar. Já na Unidade II, começam a diferenciar as características de diferentes exercícios e finalidades do treinamento aeróbico (caminhada/corrida) e do treinamento de força

\footnotetext{
está pautada nos temas estruturadores desenvolvidos durante os três anos ("sequência" curricular). A título de esclarecimento, a unidade de jogos populares teve por objetivo resgatar parte do acervo cultural produzido pelas gerações que nos antecederam (jogos e brincadeiras). Essa unidade foi desenvolvida na forma de projeto, sendo que os alunos elaboraram um desenho (projeto) de um carrinho de rolimã/lomba, construíram os carrinhos, testaram os mesmos, realizaram um km de arrancada (regras criadas por eles) e produziram um informe final através de um vídeo (filme), como forma de sistematizar todas as etapas de desenvolvimento do projeto.

${ }^{6}$ Para exemplificar, utilizamos os dados coletados junto aos alunos de apenas um curso técnico integrado ao ensino médio. Dos 103 alunos, apenas 21 (vinte e um) ficaram acima do ponto de corte (zona saudável), segundo critérios estabelecidos pelo Projeto Esporte Brasil (PROESP, 2018). Fator que se agrava, se considerarmos a questão de gênero, uma vez que das 57 meninas, apenas 1 (uma) alcançou os padrões considerados saudáveis. Resultados que, a nosso ver, se constituem em um caso preocupante de saúde pública.
} 
(musculação) (conceitos, tipos de treino, benefícios, locais), o que lhes proporciona uma leitura (conceitual e corporal) dos efeitos desses treinamentos em seu organismo e as possibilidades de realização nos períodos extraclasse. Para finalizar, na Unidade III os alunos apropriam-se dos princípios do treinamento esportivo (abordados em forma de trabalho individual e discutidos em aula) e são desafiados a elaborar um programa de exercícios para a melhoria de sua condição física, desenvolvido em período extraclasse, com registros das atividades em um diário de exercícios físicos (observando critérios, como duração, frequência e intensidade).

Ao final do desenvolvimento de cada unidade didática, os alunos produzem um informe final ("texto informativo") do trabalho realizado, relacionando os saberes conceituais e corporais, e analisam as contribuições desse tema para a sua vida, como podemos perceber em alguns trechos da avaliação dos mesmos.

\begin{abstract}
Conforme a passagem das aulas notei a diferença em minha resistência durante as corridas e a realização dos exercícios, a mudança na minha respiração e o aumento da transpiração dependendo do exercício realizado e desconforto muscular e cansaço em algumas aulas. As práticas estão sendo eficientes tanto pro meu condicionamento físico quanto para minha saúde, contribuiu para conhecer meus próprios limites em determinados exercícios (Bruna ${ }^{7}$, aluna do $1^{\circ}$ ano).
\end{abstract}

Observando o que cada um dos dois trabalhos (aeróbico e de força) pode nos proporcionar, eu optaria por montar um treinamento específico utilizando o trabalho de força. Essa minha escolha surge a partir da necessidade que sinto muitas vezes enquanto pratico esportes, vejo que minha forma física não permite ganhar alguns lances que envolvem maior utilização de força e contato físico. Além do mais, o trabalho aeróbico está mais presente no meu dia a dia, enquanto o trabalho de força seria algo mais recente e desconhecido, que auxiliaria na minha prática esportiva (Roberto, aluno do $2^{\circ}$ ano).

A partir das práticas e explanações, tenho algum tipo de discernimento para montar um diário de exercícios a fim de melhorar minha saúde praticamente sozinha, pois até então não conhecia a maior parte dos princípios de treinamento esportivo e o modo como esses devem ser aplicados, em boa parte do tempo quando procurava fazer atividades físicas, acabava por fazer de maneiras totalmente erradas que ao invés de me auxiliarem somente prejudicavam (Suzana, aluna do $3^{\circ}$ ano)

A partir da análise dos alunos, percebemos como se apropriam dos temas abordados e experienciados em aula, construindo alguns referenciais para analisar, compreender e perceber os efeitos dos exercícios físicos, as alterações provocadas no próprio corpo (sensações corporais), a escolha de determinado treinamento para alcançar seus objetivos e como podem incorporar um programa de exercícios em seu cotidiano.

De nossa parte, entendemos que proporcionamos aos alunos uma relação de maior proximidade com a temática das unidades, em especial no tratamento com os saberes corporais

\footnotetext{
${ }^{7}$ Utilizamos nomes fictícios para preservar a identidade dos alunos e também para não identificar os cursos a que pertencem, apenas a "série".
} 
(em que os alunos sentiram "na pele" os efeitos dos exercícios) e os saberes conceituais "conhecimentos técnicos" (em que os mesmos entenderam as características e o funcionamento operacional da unidade de exercícios). Porém, não conseguimos dar conta (com maior aprofundamento) dos "conhecimentos críticos" em todas essas unidades, de maneira mais sistematizada, apenas com alguns apontamentos mais "superficiais" em relação aos temas padrões de beleza, estética X saúde e o uso de esteroides anabolizantes (por exemplo).

Com relação ao tema estruturante dos Esportes, da mesma forma, pensamos em organizar nossa proposta de intervenção em três unidades distintas: Unidade de esportes I, Unidade de esportes II e Unidade de esportes III. Para uma perspectiva mais ampliada da temática, adotamos uma classificação elaborada por González (2006, p. 117), que nos permite localizar os diferentes tipos de esportes e as demandas exigidas em cada modalidade, em função de quatro categorias: “a) a relação com o adversário; b) as possibilidades de cooperação; c) as características do ambiente físico onde se realiza a prática esportiva; d) os objetivos táticos da ação nos esportes com interação; e) a lógica de comparação de desempenho nos esportes sem interação".

Essa classificação permite-nos estabelecer alguns critérios para organizar os tempos destinados à abordagem de cada esporte, considerando os diferentes tipos de saberes a ser contemplados. Nos esportes que possuem potencial para os alunos usufruírem em seus tempos livres (lazer), abordamos os saberes corporais - "para saber praticar" e os saberes conceituais conhecimento técnico, regras de ação, princípios operacionais, sistemas de jogo, etc. conhecimento crítico, as influências da mídia na organização esportiva, a questão de gênero no esporte, doping, etc., destinando um tempo maior para o tratamento dessas potencialidades, como é o caso dos esportes de invasão (unidades I, II e III) e esportes de quadra dividida (unidades II e III). Já nos esportes estéticos ou técnico-combinatórios e de campo e taco (unidade I), de precisão (unidade II) e de marca (unidade III), optamos por uma abordagem “com menor ênfase" (menor número de aulas) nos saberes corporais - "para conhecer" e os saberes conceituais - conhecimento técnico, princípios que orientam tais esportes conhecimento crítico, dimensões culturais e os espaços destinados a essas modalidades ${ }^{8}$.

\footnotetext{
${ }^{8}$ Cabe enfatizar que estamos atentos ao alerta de González e Fraga (2009), ao nos convidarem para refletir sobre a dinâmica de reprodução cultural, para não corrermos o risco de simplesmente reproduzir os esportes "mais praticados" no entorno imediato dos alunos, da mesma forma que não podemos reproduzi-los como são tratados no ambiente extraescolar.
} 
Ao visualizar os tempos destinados a essas unidades (quadros 1, 2, e 3), nossa proposta pode parecer ainda muito esportivizada; por outro lado, percebemos uma ampliação do universo esportivo dos alunos (para além de uma monocultura) e o tratamento pedagógico dado ao esporte, que leva em consideração as suas dimensões sociais propostas por Tubino (2001) (esporte-educação ou escolar, esporte-participação ou de lazer e esporte-performance ou de alto rendimento), algo que acaba diferenciando sua abordagem (na escola) diferentemente de outros espaços sociais. Esse tratamento pedagógico pode potencializar (tem potencializado) uma leitura mais alargada (e crítica) acerca das possibilidades e limites em relação ao fenômeno chamado "esporte", como podemos perceber nas falas dos alunos.

Aprendi que para qualquer tipo de esportes é necessário diferenciar a técnica e tática, e seus fundamentos básicos para praticar de maneira correta; aprendi a jogar alguns esportes que eu nem sabia da existência, ex.: beisebol e acabei gostando muito (Laura, aluna do $1^{\circ}$ ano, DIÁRIO DE CAMPO).

Muito interessante a forma como os esportes foram trabalhados com a nossa turma, incluindo todos sem que ninguém fique de fora, trabalhando tanto a parte tática quanto técnica (Carlos, aluno do $1^{\circ}$ ano, DIÁRIO DE CAMPO).

Abrange modalidades que muitos dos alunos desconheciam e não tinham contato, e no entanto, tiveram essa oportunidade [...] outro aspecto positivo foi a realização dos torneios de algumas modalidades ${ }^{9}$, fazendo com que a maioria da turma participasse e desenvolvesse o interesse pelos esportes (Gabrieli, aluna do $2^{\circ}$ ano, DIÁRIO DE CAMPO)

[...] outro aspecto destacável é o conhecimento do esporte frisbee por ser novo culturalmente para nós, por tratar de fatores como ética, respeito e a diversão atrelados, uma competição sadia e uma ótima experiência (Luana, aluna do $3^{\circ}$ ano, DIÁRIO DE CAMPO).

Por fim, no tema estruturante Práticas Corporais de Aventura, organizamos o trabalho em Unidade de práticas de aventura I, II e III (também referindo-se, respectivamente, aos três anos do ensino médio técnico integrado). Na primeira unidade (primeiros anos), optamos por iniciar o trabalho com práticas de aventura mais simples e com condições de tematizá-las pedagogicamente no espaço disponível que temos para nossas aulas: slackline e corrida de orientação. Na sequência, na segunda unidade (segundos anos), desenvolvemos o "Projeto Jangada" ${ }^{\text {, }}$ que ocorreu em um espaço fora das dependências do campus, com a construção de

\footnotetext{
${ }^{9}$ Ao final das Unidades de esportes de invasão e de quadra dividida (unidades II e III), realizamos torneios internos das modalidades abordadas em que os alunos fizeram uma preparação para os mesmos, que foi desde a preparação da equipe até a sua organização e arbitragem. Ao final produziram uma análise em grupo (da equipe) e uma análise individual de sua participação na Unidade.

${ }^{10}$ O Projeto Jangada teve/tem como objetivo "proporcionar aos alunos um momento coletivo de organização, planejamento e construção de uma jangada, utilizando somente materiais alternativos (garrafas pet, taquara, câmaras de ar, cordas, etc.) para que possam vivenciar uma atividade aquática e/ou práticas corporais junto à natureza nas aulas de Educação Física e auxiliar na construção do seu próprio processo de ensino e aprendizagem". Os alunos elaboram o projeto (desenho, materiais utilizados) e realizam a construção da jangada em local fora das dependências da instituição. Após a construção, realizam os testes de navegação e
} 
embarcações alternativas (com material reutilizável) e utilização de caiaques e pranchas de Stand Up Paddle (SUP). Terminamos essa unidade (terceiros anos) proporcionando aos estudantes experiências em práticas de aventura mais complexas e num espaço formal e próprio para tal, tais como escalada, rapel, tirolesa e arvorismo.

Nessas unidades, a fruição das práticas e a superação de limites dos estudantes são a tônica das aulas, tendo em vista que as práticas corporais de aventura possuem como características a vertigem e o risco controlado proporcionado pelo ambiente durante a sua realização, em especial as que são vinculadas ao contato íntimo com a natureza e às incertezas do ambiente. Quando ouvimos de vários estudantes o quanto ficaram satisfeitos e realizados ao finalizar o "projeto jangada", e ao percebermos nas suas falas a importância que essas aulas exerceram nas suas vidas, acreditamos que estamos proporcionando aos nossos alunos momentos únicos de acesso à pluralidade de manifestações relacionadas à cultura corporal de movimento, contemplando saberes que extrapolam a simples fruição, mas potencializando uma leitura mais lúcida em relação ao mundo; nesse caso, em especial, as relações que foram estabelecidas com experiências que os alunos não tiveram acesso em sua vida escolar (e extraescolar também), como percebemos em seus depoimentos.

A aula foi muito interessante e produtiva, pois colocamos em prática a atividade de corrida de orientação, algo que eu e acho que também meus colegas nunca haviam praticado antes. Nessa aula quem não sabia usar a bússola aprendeu, e achei interessante "medir" os passos. Agora tenho uma noção básica de como me orientar (Jaline, aluna do $1^{\circ}$ ano, DIÁRIO DE CAMPO).

Nunca imaginei que o slackline fizesse parte da educação física e muito menos que eu ia conseguir ficar em cima da fita... (Jéssica, aluna do $1^{\circ}$ ano, DIÁRIO DE CAMPO).

A aula foi muito incrível! O lugar foi muito perfeito! Foi a melhor aula de educação física da minha vida! (Amanda, aluna do $2^{\circ}$ ano, DIÁRIO DE CAMPO).

Professor eu estava aguardando esse momento desde o ano passado em que o senhor apresentou os conteúdos que seriam desenvolvidos nos 3 anos do nosso curso. Nunca imaginei passar por essa experiência, pois oportunidade como essa não sei se irei ter (Vanusa, aluna do $2^{\circ}$ ano, DIÁRIO DE CAMPO).

Apresentamos alguns depoimentos dos alunos em relação ao desenvolvimento das unidades I e II das práticas corporais de aventura, uma vez que, por problemas de logística (falta de verbas e transporte), não conseguimos realizar a unidade III, algo que nos faz pensar em algumas estratégias para garantir o desenvolvimento da unidade, junto aos alunos do $3^{\circ}$ ano;

em seguida há uma corrida de jangadas (turno da manhã). À tarde, experienciam a prática da canoagem e do SUP. Ao final da unidade produzem um vídeo (filme), desde o desenho, coleta de materiais, realização dos testes, corrida das jangadas, vivências de canoagem e SUP e apresentam para a turma. 
porém, ainda assim acreditamos ter proporcionado experiências significativas (únicas) aos nossos alunos em relação à temática, que extrapolaram o seu imaginário acerca da EF.

Analisando nossa proposta de intervenção, de maneira mais atenta e cuidadosa, podemos destacar alguns fatores limitantes que dificultaram/dificultam a consolidação da mesma durante o seu desenvolvimento, a saber: dificuldade de estabelecer uma relação entre o tempo disponível e o tempo necessário para a abordagem dos temas estruturantes e diferentes tipos de saberes, em especial os saberes conceituais - conhecimento crítico, que foram tematizados de maneira mais superficial; a não abordagem de alguns temas estruturantes, como é o caso das práticas corporais expressivas - dança e das lutas; dificuldades em desenvolver a mesma proposta para cursos distintos que possuem cargas horárias diferentes para a Educação Física (que critérios utilizar para fazer "cortes" ou "eleger" os saberes que consideramos fundamentais no processo de ensino e aprendizagem de nossos alunos?); dificuldades de articular e/ou vincular as especificidades de nosso campo de tematização ao currículo integrado (e à educação profissional e tecnológica de forma realmente integrada).

Pensando nessas dificuldades apontadas, começamos a esboçar algumas possíveis "soluções" (mesmo que parciais) para os problemas considerados "entraves" para o desenvolvimento de nossa proposta. A questão do tempo necessário e o tempo disponível para o desenvolvimento das unidades didáticas também é apontada pela maioria dos alunos (nas avaliações realizadas) como o principal aspecto negativo das aulas. No que se refere ao desenvolvimento do mesmo "programa" em turmas com cargas horárias diferentes, acabamos fazendo uma abordagem mais superficial de algumas unidades didáticas, mesmo naquelas que indicam um tempo maior para as práticas corporais "para saber praticar"; nas turmas com 40 horas, acabamos realizando uma abordagem dessas práticas "para conhecer". A questão do tempo e distribuição das cargas horárias nos diferentes cursos é uma condição de nossa tarefa educativa e, por isso mesmo, nos convoca a pensar em estratégias para o desenvolvimento de cada unidade; por outro lado, ficamos na expectativa de reformulações dos projetos de curso, e que possamos dialogar com nossos pares para uma redistribuição das cargas horárias de forma mais igualitária, sustentada por uma proposição consolidada em nosso campo de tematização.

A questão do tempo necessário e o tempo disponível (nos diferentes cursos) também nos levou a não optar pela abordagem das práticas corporais sistematizadas - dança e das lutas em nossa proposta de intervenção (desenvolvida em 2019), algo que, no nosso entendimento, privou nossos alunos de uma experiência com essas temáticas, devido ao seu grande potencial 
educativo. Reconhecer esses limites nos leva/levou a uma reformulação de nossa proposta e à inclusão dessas práticas corporais em uma nova proposição a ser desenvolvida no ano de 2020.

Por fim, entendemos que a nossa maior limitação e/ou dificuldade está na abordagem da Educação Física enquanto disciplina escolar (de forma integrada); afinal, o que diferencia (ou deveria diferenciar) o ensino médio básico dos cursos técnicos integrados ao ensino médio é justamente essa integração curricular. Porém, entendemos que essa não é uma dificuldade apenas da EF, mas de toda a educação profissional e tecnológica, uma vez que ainda estamos pensando na lógica de conhecimentos disciplinares. Os próprios Institutos Federais vêm discutindo a implementação do currículo integrado desde a sua criação (BRASIL, 2008); porém, o que acontece, via de regra, é que essas discussões ainda ocorrem no plano discursivo, pelo menos não temos acesso às experiências consolidadas de forma mais efetiva no plano da ação. O currículo integrado, para Santomé (1998), é uma tentativa de contemplar a compreensão macro do conhecimento e de promover maiores parcelas de interdisciplinaridade na sua construção, porém reconhecemos que a interdisciplinaridade é apenas um dos princípios que norteiam o currículo integrado, mas não o único.

Nesse sentido, o nosso desafio maior está em vincular os temas/conteúdos específicos de nosso campo de tematização a diferentes áreas do conhecimento, em especial às disciplinas técnicas de distintos cursos, projetando uma tentativa de interdisciplinaridade como um primeiro passo na integração de conhecimentos gerais e específicos relacionados à educação básica e profissional. Talvez essa seja uma das estratégias possíveis (ainda que provisória) para a integração curricular, uma vez que nossas propostas de currículo integrado (em sua maioria) ainda estão estruturadas em disciplinas fragmentadas (STERING; ADAM, 2019).

Reconhecer essas limitações permite-nos uma leitura crítica do trabalho que estamos realizando, além da possibilidade de apresentar possíveis "soluções" para essa integração. Temos feito um movimento junto aos coordenadores de curso e professores interessados em participar dessa construção coletiva, no sentido de estudar as "grades curriculares" dos diferentes cursos, numa tentativa de buscar possíveis vínculos nas ementas de cada disciplina para consolidar uma articulação de diferentes áreas do conhecimento, tomando o cuidado para o tratamento dado ao conhecimento e às especificidades de cada campo de tematização, para não corrermos o risco de instrumentalizarmos as mesmas (uma estar a "serviço" da outra).

\section{CONSIDERAÇões FinAIS}


Acreditamos que o desenvolvimento de nossa proposta de intervenção possibilitou-nos uma leitura mais criteriosa acerca de suas possibilidades e limites, uma vez que permitiu identificar os problemas e "entraves" de nossa proposição, pensar em possíveis "soluções" e fazer os enfrentamentos necessários para a sua "resolução" (mesmo que temporária ou provisoriamente). A metodologia da pesquisa-ação tem-se mostrado uma perspectiva muito interessante, que nos permitiu/permite um movimento contínuo, sistemático e renovado para repensar (constantemente) nossa tarefa educativa, reafirmar a importância do nosso protagonismo e a continuidade do exercício da crítica. Porém, é necessário tomarmos cuidado para não banalizar a pesquisa-ação, tomando-a como um modo qualquer de intervenção, direta ou indireta das práticas pedagógicas; ao contrário, devemos abordá-la com referências criteriosas em seus diferentes aspectos (ontológico, epistemológico e metodológico), além do envolvimento dos sujeitos em todas as "etapas" da investigação (VENÂNCIO; SANCHES NETO; BETTI, 2018).

Dentre os limites apontados em nosso estudo, destacamos a falta de integração curricular como o maior desafio a ser enfrentado, não só pela EF, mas pela educação profissional e tecnológica de forma mais ampla. De nossa parte, entendemos que promover "parcelas" de interdisciplinaridade pode ser o primeiro passo para pensarmos em integração curricular, pelo menos enquanto nossos "currículos integrados" estiverem organizados na forma de disciplinas fragmentadas.

Na reformulação de nossa proposta de intervenção, além de incluir as práticas corporais expressivas - dança, estamos projetando uma unidade didática coletiva ${ }^{11}$ (com esse tema estruturante) articulando-a à área de Linguagem, Códigos e Suas Tecnologias (Língua Portuguesa, Literatura, Língua Estrangeira - Inglês ou Espanhol, Artes, Educação Física e Tecnologias da Informação e Comunicação) e às áreas de caráter técnico, em uma tentativa de articulação de conhecimentos gerais e específicos relacionados à educação básica e profissional. Reconhecemos os limites dessa tentativa de "integração" curricular; por outro lado, essa relação pode nos fornecer algumas pistas para potencializar um debate mais amplo para a construção de uma proposta de formação integrada, que considere a integração epistemológica, de conteúdos, de metodologias e de práticas educativas (BRASIL, 2007).

\footnotetext{
${ }^{11}$ Temos feito esse movimento de tentar articular outras unidades didáticas através da integração de conhecimentos gerais e específicos relacionados à educação básica e profissional.
} 
Nos limites de nossa proposta encontramos algumas dificuldades e "entraves" no desenvolvimento de nossas proposições; nas possibilidades, vislumbramos um caminho promissor de constantes mudanças e revisões de nosso projeto curricular, afinal essa construção não se dá de vez (de forma definitiva), mas a cada vez, na contingência de nossa ação interventiva e reflexiva, no tratamento dado ao caráter processual do conhecimento e no diálogo constante e sempre renovado pela crítica dos pares. Seguimos...

\section{REFERÊNCIAS}

ALMEIDA, Luciano de; FENSTERSEIFER, Paulo Evaldo. Indicativos para pensar uma proposta para a Educação Física escolar: da elaboração ao diálogo com a intervenção. Lúdica Pedagógica, v. 1, n. 28. Disponível em:

https://revistas.pedagogica.edu.co/index.php/LP/article/view/9430. Acesso em: 03 jan. de 2019.

ALMEIDA, Luciano de; FENSTERSEIFER, Paulo Evaldo. A relação teoria-prática na educação física escolar: desdobramentos para pensar um "programa mínimo". Kinesis, v. 32, n. 2, dez. 2014. Disponível em: https://periodicos.ufsm.br/kinesis/article/view/16503. Acesso em: 06 out. 2018.

ALMEIDA, Luciano de; FENSTERSEIFER, Paulo Evaldo. O que ensinar e aprender nas aulas de educação física na escola? Revista Digital Efdeportes, Buenos Aires, ano 11, n, 102, novembro, 2006. Disponível em: https://www.efdeportes.com/efd102/aulasef.htm. Acesso em: 10 out. 2018.

BARDIN, L. Análise de conteúdo. 6 ed. Lisboa: Edições 70, 2011.

BETTI, Mauro. O que a semiótica inspira ao ensino da educação física. Discorpo, São Paulo, n. 3, p. 25-45, 1994.

BETTI, Mauro; FRANCO, Maria Amélia Santoro. Pesquisa-ação. In: GONZÁLEZ, Fernando Jaime; FENSTERSEIFER, Paulo Evaldo. (Orgs.). Dicionário crítico de educação física. 3. edição revisada e ampliada. Ijuí: Unijuí, 2014. p. 502-508.

BRACHT, Valter. Educação física \& ciência: cenas de um casamento (in)feliz. 2. ed. Ijuí: Ed. Unijuí, 2003.

BRASIL. Ministério da Educação. Secretaria de Educação Básica. Base Nacional Comum Curricular. Brasília, 2017.

BRASIL. Ministério da Educação. Secretaria de Educação Básica. Base Nacional Comum Curricular. $2^{\mathrm{a}}$ versão. Brasília, 2016.

BRASIL. Casa Civil. Lei n. 11.892 de 29 de dezembro de 2008. Institui a Rede Federal de Educação Profissional, Científica e Tecnológica e cria os Institutos Federais de Educação, Ciência e Tecnologia. 2008. 
BRASIL. MEC. Educação Profissional Técnica de Nível Médio Integrada ao Ensino Médio. Documento base. Brasília, 2007.

BRASIL. Parâmetros Curriculares Nacionais: educação física. Brasília: Secretaria de Educação Fundamental, 1998.

COLETIVO DE AUTORES. Metodologia do ensino da educação física. São Paulo: Cortez, 1992.

FENSTERSEIFER, Paulo Evaldo; GONZÁLEZ, Fernando Jaime. Educação Física escolar: a difícil e incontornável relação teoria e prática. Motrivivência. Florianópolis, ano 19, n. 28, p. 27-37, jul. 2007. Disponível em:

https://periodicos.ufsc.br/index.php/motrivivencia/article/view/9123/9549. Acesso em: 26 jan. 2019.

GADAMER, Hans-Georg. Verdade e método I: traços fundamentais de uma hermenêutica filosófica. Tradução de Flávio Paulo Meurer; revisão da tradução de Enio Paulo Giachini. 10. ed. Petrópolis, RJ: Vozes, 2008.

GONZÁLEZ, Fernando Jaime. Sistema de classificação dos esportes. In: REZER, R. (Org.): O fenômeno esportivo: ensaio crítico-reflexivos. Chapecó: Argos, 2006. p. 111-121.

GONZÁLEZ, Fernando Jaime; FENSTERSEIFER, Paulo Evaldo. Entre o "não mais" e o "ainda não": pensando saídas do "não-lugar" da EF escolar II. Cadernos de Formação RBCE. v.1, n. 2, p. 10-21, mar. 2010. Disponível em: http://revista.cbce.org.br/index.php/cadernos/article/view/978/561. Acesso em: 29 mai. 2018.

GONZÁLEZ, Fernando Jaime; FENSTERSEIFER, Paulo Evaldo. Entre o "não mais" e o "ainda não": pensando saídas do "não-lugar" da EF escolar I. Cadernos de Formação RBCE. v. 1, n. 1, p. 9-24, set. 2009. Disponível em: http://revista.cbce.org.br/index.php/cadernos/article/view/929/539. Acesso em: 29 mai. 2018.

GONZÁLEZ, Fernando Jaime; FRAGA, Alex Branco. Afazeres da Educação Física na Escola: planejar, ensinar, partilhar. Erechim: Edelbra, 2012.

GONZÁLEZ, Fernando Jaime; FRAGA, Alex Branco. Referencial Curricular de Educação Física. In: RIO GRANDE DO SUL. Secretaria de Estado da Educação. Departamento Pedagógico. (Org.). Referenciais Curriculares do Estado do Rio Grande do Sul: Linguagens, Códigos e suas Tecnologias. Porto Alegre: SE/DP, 2009, v. 2, p. 111-181.

KUNZ, Elenor. Transformação didático-pedagógica do esporte. 4. ed. Ijuí: Ed. Unijuí, 2000 .

MALDANER, Otávio Aloísio. A formação inicial e continuada de professores de Química: professores/pesquisadores. Ijuí: Editora Unijuí, 2006.

PROJETO ESPORTE BRASIL. Disponível em: https://www.ufrgs.br/proesp Acesso em: 20 jul. 2018.

SACRISTÁN, José Gimeno. O currículo: uma reflexão sobre a prática. Porto Alegre: Artmed, 2000. 
SACRISTÁN, José Gimeno; GÓMEZ, Ángel I. Perez. Compreender e transformar o ensino. 4. ed. Porto Alegre: ArtMed, 1998.

SANTOMÉ, Jurjo Torres. Globalização e Interdisciplinaridade: o currículo integrado. Porto Alegre: Artes Médicas, 1998.

STERING, Silvia Maria Santos; ADAM, Joyce Mary. A reforma do ensino médio por meio da lei $\mathrm{n}^{\circ} 13.415 / 2017$ e seus impactos no ensino médio integrado dos institutos federais. Revista Prática Docente, Confresa, v. 4, n. 2, p. 869-886, jul/dez 2019. Disponível em: http://periodicos.cfs.ifmt.edu.br/periodicos/index.php/rpd/article/view/560/232. Acesso em: 20 jan. 2020.

THIOLLENT, Michel. Metodologia da pesquisa-ação. 18. ed. São Paulo: Cortez, 2011.

TRIPP, David. Pesquisa-ação: uma introdução metodológica. Educação e Pesquisa, São Paulo, v. 31, n. 3, p. 443-466, set./dez. 2005. Disponível em:

http://www.scielo.br/pdf/ep/v31n3/a09v31n3.pdf. Acesso em 03 jun. 2019.

TRIVIÑOS, Augusto Nibaldo Silva. Introdução a pesquisa em Ciências Sociais: a pesquisa qualitativa em educação. São Paulo: Atlas, 1987.

TUBINO, Manoel José Gomes. Dimensões sociais do esporte. 2. ed. São Paulo: Cortez, 2001.

VENÂNCIO, Luciana; SANCHES NETO, Luiz; BETTI, Mauro. Perspectivas da PesquisaAção na Educação Física Escolar: indícios a partir de programas de pós-graduação. Revista Estreiadialogos, Braga, n. 1, p. 123-140, jul. 2018. Disponível em: https://8835c378-42a14ae0-9760-

5ce4b8d2d152.filesusr.com/ugd/eb8d33_4b6a51d4f11a49049dfefe0ca7b0218c.pdf. Acesso em: 19 mar. 2020.

Recebido em: 28 de fevereiro de 2020 .

Aprovado em: 30 de março de 2020. 